EESTI NSV TEADUSTE AKADEEMIA TOIMETISED, 20. KÖIDE

KEEMIA * GEOLOOGIA, 1971, NR. 3

ИЗВЕСТИЯ АКАДЕМИИ НАУК ЭСТОНСКОЙ ССР. ТОМ 20

ХИМИЯ * ГЕОЛОГИя. 1971, № 3

удК $553.551 .1: 691(474.2)$

Э. КИВИМЯГИ, ААДА ТЕЕДУМЯЭ

\title{
РЕЗУЛЬТАТЫ КОМПЛЕКСНОЙ ОЦЕНКИ ВСКРЫШНЫХ ПОРОД МЕСТОРОЖДЕНИЯ ФОСФОРИТОВ ТООЛСЕ
}

Комплексное использование месторождений полезных ископаемых является важной народнохозяйственной задачей, поскольку оно расширяет сырьевую базу, сокращает потери минерального сырья, улучшает технико-экономические показатели добычи и снижает капиталовложения в горнодобывающую промышленность. Научно-техническоє совещанне по этой проблеме, проведенное в декабре 1970 г. Академией наук СССР и Государственным комитетом СМ СССР по науке и технике, считает снижение потерь полезных ископаемых и комплексное использование минерального сырья основным іаправлением работы государственных министерств и ведомств при разработке месторождений полезных ископгемых и их первичной переработке. На территории ЭССР имеются месторождения, эффекгивность комплексной разработки которых заслуживает большого внимания. К ним относятся месторождения горючих сланцев и фосфоритов. В покрывающей толще первых промышленное значение имеют торф и карбонатные породы (Бауков, 1970), а в покрывающей толще фосфоритов - граптолитовые аргиллиты (диктионемовые сланцы), глауконитовые и карбонатные породы.

На открытом в начале 60 -х годов месторождении фосфоритов Тоолсе, расположенном юго-западнее г. Кунда (рис. 1), в настоящее время Управлением геологии СМ ЭССР проводятся детальные геологоразведочные работы. На этом же месторождении авторами были проведены в 1969-1970 гг. специальные исследования по комплексному использованию вскрышных пород месторождения, где основное внимание уделялось геологическому изучению и качественной характеристике граптолитовых аргиллитов (Э. Кивимяги), а также геологоэкономической оценке возможностей комплексного использования вскрышных пород фосфоритов (А. Теедумяэ).

Месторождение фосфоритов Тоолсе сложено разнообразной толщей коренных пород нижнего и среднего ордовика (рис. 2). Непосредственно на фосфоритоносных отложениях маардуской пачки (средняя мощность около $5 \mathrm{M}$ ) пакерортского горизонта $\left(\mathrm{A}_{n}\right)$ залегают (снизу вверх): граптолитовые аргиллиты, глинистые и глауконитовые породы (перспективные полезные ископаемые нижнего ордовика) и карбонатные породы разных горизонтов, которые также представляют интерес как полезные ископаемые. Коренные породы месторождения покрыты маломощным (в среднем 1,0 м) слоем четвертичных отложений. Суммарная мощность вскрышных пород месторождения составляет в среднем 20-25 м.

К арбонатные породы месторождения Тоолсе составляют до $80-85 \%$ (средняя мощность $15-20$ м) обшего объема вскрышных пород и представлены разными по качеству известняками и доломитами. Наиболее качественными являются карбонатные породы среднего ордовика. Они могут быть использованы для изготовления цемента как само- 

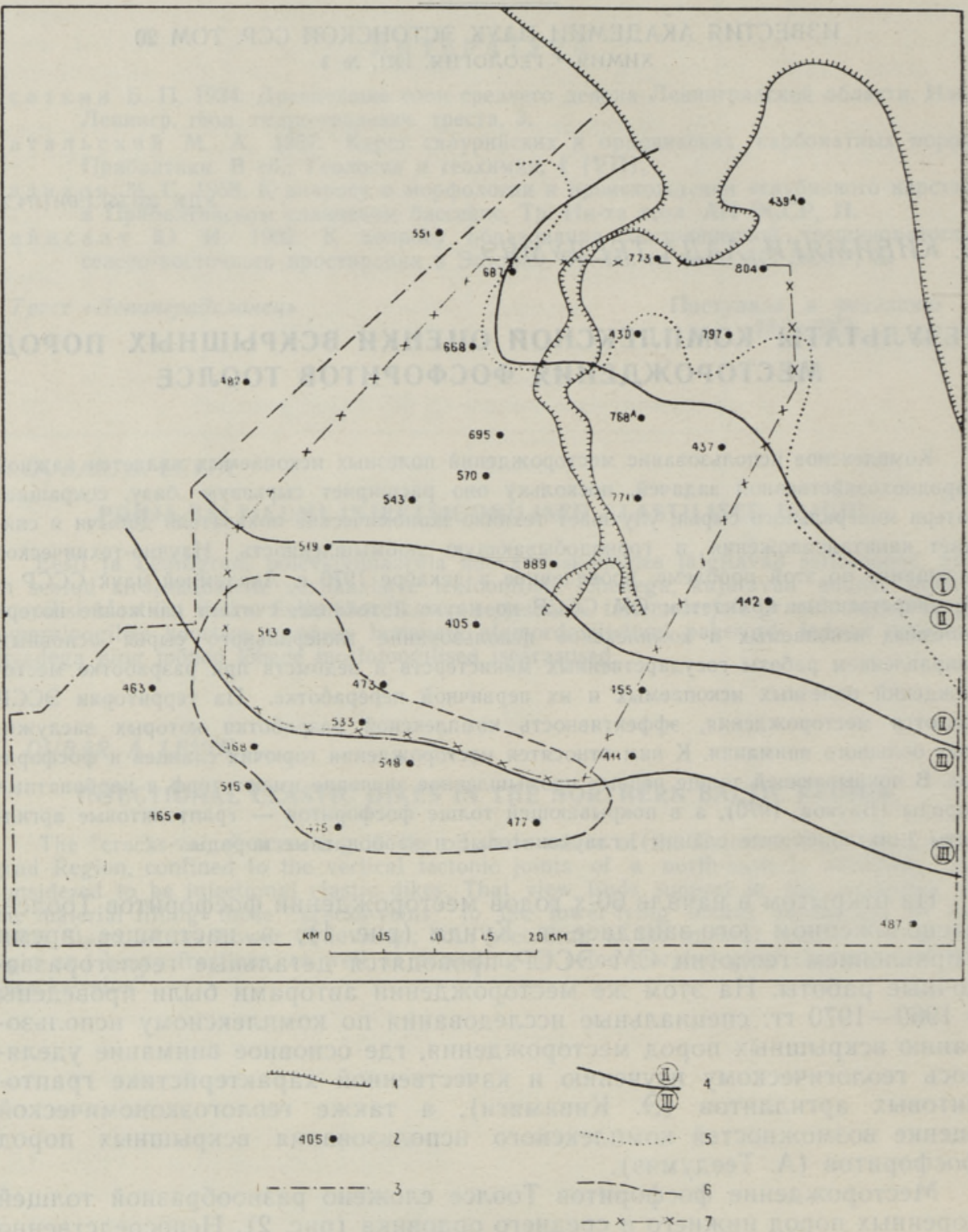

Рис. 1. Схема месторождения Тоолсе.

1 - уступ в коренных породах: 2 - буровая скважина и ее номер: 3 - коитур разведанных запасов фосфоритов кат. $\mathrm{C}_{2} ; 4$ - границы и номер горнотехннческих $30 н ; 5-1$ южная граница ыыхода пород нижнего ордовика; 6 - граница участка наиболее качественных аргиллитов; 7 - контур намечаемого карьера.

стоятельно (верхняя часть ласнамягиской свиты), так и в естественной пропорции с залегающими выше породами ухакуской свиты, а также для производства щебня и в качестве строительного (бутового) камня (породы ласнамягиской свиты и азериских слоев)*. Карбонатные породы

* Согласно обязательной для Управл. геол. СМ ЭССР стратиграфической схеме Прибалтийской серии ластов Государственной геологической карты. 

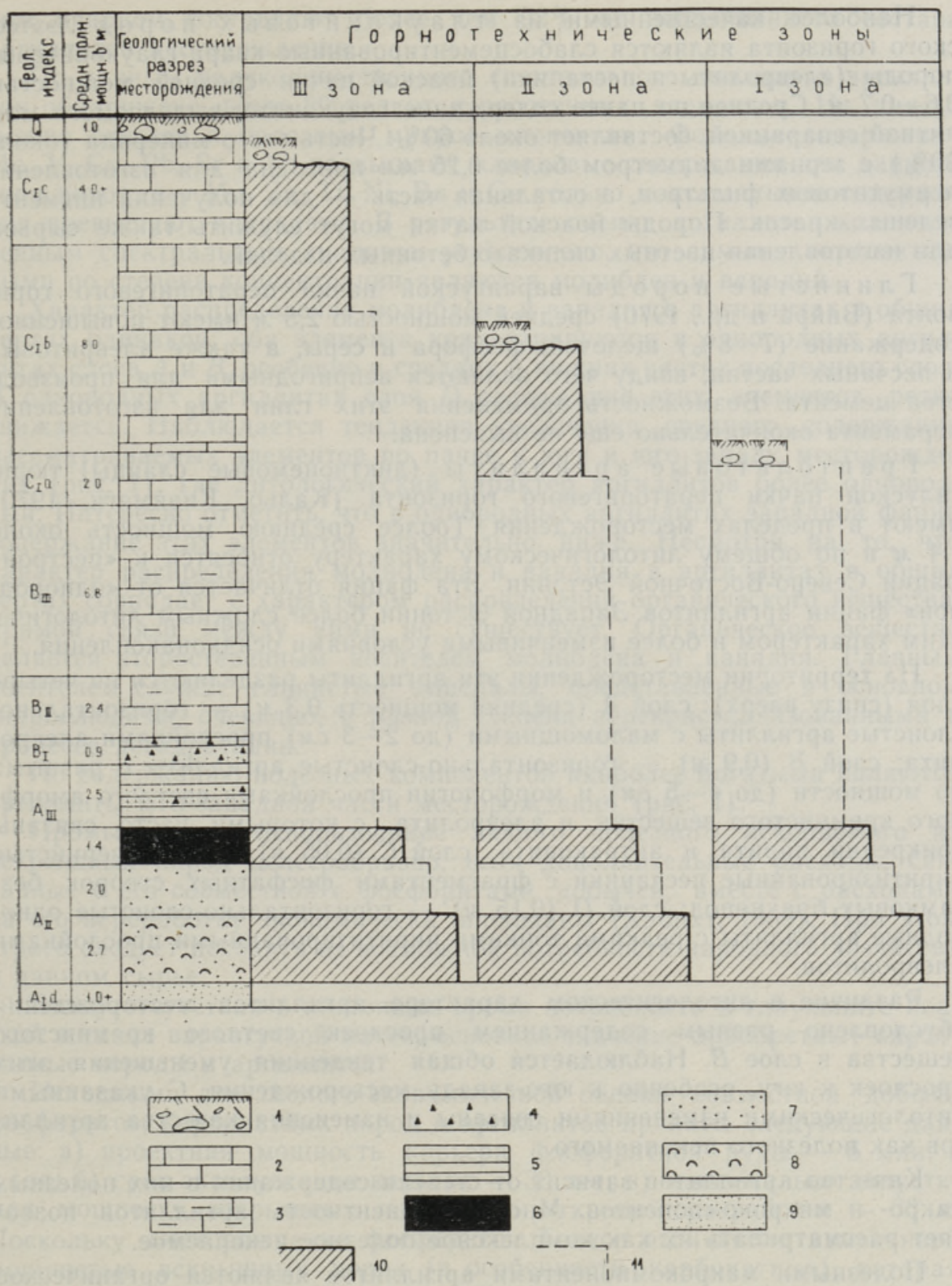

Рис. 2. Схема комплексной разработки месторождения Тоолсе.

I - четвертичные отложения и почва; 2 - карбонатные породы среднего ордовика, пригодные для использования в условиях валовой выемки: 3 - карбонатные породы нижнего ордовика, не пригодные для использования в условиях валовой выемки: 4 - глауконит; 5 - глинистые породы; 6 - аргиллиты; 7 - разнозернистые песчаники: 8 - фосфатные стнорки брахиопод; 9 - алевролиты; 10 - уступ в породах, предназначенных для добычи: II - уступ в породах, выбрасываемых в отвал по бестранспортной схеме.

нижнего ордовика (кундаский и волховский горизонты) ввиду содержания значительного количества глинистых и мергелистых прослоек при валовой их выемке не могут служить сырьем для производства строительных материалов. 
Наиболее качесгвенными из глауконитовых пород лээтсеского горизонта являются слабосцементированные кварц-глауконитовые породы (алевролиты и песчаники) йоаской пачки средней мощностью $0,6-0,7$ м. Среднее по пачке содержание глауконита, выделяемого магнитной сепарацией, составляєт около $60 \%$. Часть этого минерала (около $20 \%$ ) с зернами диаметром более 0,25 мм пригодна для изготовления пермутитовых фильтров, а остальная часть - для получения пигмента зеленых красок. Породы йоаской пачки могут служить также сырьем для изготовления цветных силикато-бетонных изделий.

Глинисты е породы варангуской пачки цератопигевого горнзонта (Вийра и др., 1970) средней мощностью 2,5 м имеют повышенное содержание $(7-8 \%)$ щелочей, фосфора и серы, а также алевритовых и песчаных частиц, ввиду чего являются непригодными для производства цемента. Возможность применения этих глин для изготовления керамзнта окончательно еще не выяснена.

Граптолитовые аргиллиты (диктионемовые сланцы) тюрисалуской пачки цератопигевого горизонта (Кальо, Кивимяги, 1970) имеют в пределах месторождения Тоолсе среднюю мощность около 1,4 м и по общему литологическому характеру относятся к «пестрой» фации Северо-Восточной Эстонии. Эта фация отличается от «однородной» фации аргиллитов Западной Эстонии более сложным литологическим характером и более изменчивыми условиями осадконакопления.

На территории месторождения эти аргиллиты разделяются на четыре слоя (снизу вверх): слой $A$ (средняя мощность $0,3 \mu)$ - горизонтальнослоистые аргиллиты с маломощными (до 2-3 cм) прослойками алевролита; слой $B(0,9$ м $)$ - горизонтально-слоистые аргиллиты с разнымй по мощности (до 4-5 cм) и морфологии прослойками светлого аморфного кремнистого вещества и алевролита, с которыми часто связаны конкреции пирита и антраконита; слой $C(0,05 \mu)$ - мелкозернистые пиритизированные песчаники с фрагментами фосфатных створок беззамковых брахиопод; слой $D(0,15 \mu)$ - горизонтально-слоистые однородные аргиллиты с редкими тонкими пиритнзированными прослойками алевролитов.

Различие в литологическом характере аргиллитов месторождения обусловлено разным содержанием прослоек светлого кремнистого вещества в слое $B$. Наблюдается общая тенденция уменьшения этих прослоек к югу, особенно к юго-западу месторождения. С указанными литологическими изменениями связаны и изменения качества аргиллитов как полезного ископаемого.

Качество аргиллитов зависит от степени содержания в них полезных макро- и микрокомпонентов. Многокомпонентность аргиллитов позволяет рассматривать их как комплексное полезное ископаемое.

Полезными макрокомпонентами аргиллитов являются органическое вещество (среднее содержание по месторождению $12,5 \%$ ), $\mathrm{Al}_{2} \mathrm{O}_{3}(8,8 \%$ ), $\mathrm{K}_{2} \mathrm{O}(5,3 \%), \mathrm{Fe}_{2} \mathrm{O}_{3}(8,5 \%)$ и $\mathrm{S}_{\text {общ }}(6,0 \%)$. Среднее содержание трех первых компонентов $\left(\mathrm{Al}_{2} \mathrm{O}_{3}\right.$ и $\mathrm{KO}_{2}$ связаны в основном с глинистыми минералами) увеличивается к югу (юго-западу), а среднее содержание остальных двух компонентов (которые связаны в основном с пиритом) - к северу месторождения. От содержания органического вещества, которое в отдельных прослойках достигает $18-19 \%$, зависят технические свойства аргиллитов. Теплотворная способность последних достигает 1600 ккал/ке. Содержание золы аргиллитов в среднем $80-81 \%$ и выход смолы $2,1-2,2 \%$. Перечисленные выше полезные макрокомпоненты с балластным компонентом $\mathrm{SiO}_{2}(51 \%)$, представленным в основ- 
ном кварцем, составляют более чем $92 \%$ от вещественного состава аргиллитов месторождения.

По данным полуколичественного спектрального анализа в аргиллитах обнаружено около 20 редких и рассеянных элементов. Из них 12 можно отнести к полезным микрокомпонентам. Фоновые содержания $\mathrm{Mo}, \mathrm{V}, \mathrm{Cu}, \mathrm{Pb}, \mathrm{Sr}$ и $\mathrm{Yb}$ превышают кларковые содержания для данного типа пород, а у $\mathrm{Mn}, \mathrm{Zn}, \mathrm{Ti}, \mathrm{Ni}, \mathrm{Ba}$ и Ga только максимальные содержания превышают кларковые. В результате оценки аргиллитов количественным спектральным анализом установлено, что самыми перспективными по степени концентрации являются молибден и ванадий.

Характер распределения молибдена и ванадия в аргиллитах в общих чертах одинаков: оба элемента концентрируются в однородных аргиллитах слоев $A$ и $B$, особенно в средних и нижних частях последнего слоя. В однородных аргиллитах слоя $D$ содержание этих элементов резко снижается. Наблюдается тенденция увеличения среднего содержания рассматриваемых элементов по пачке к югу и юго-западу месторождения (рис. 1), где литологический характер аргиллитов более однородный. Интересно отметить, что в однородных аргиллитах западной фации содержание этих элементов значительно ниже. Несмотря на то, что характер распределения молибдена и ванадия в аргиллитах в общих чертах совпадает с характером распределения органического вещества, прямой связи между ними не существует. Органическое вещество является второстепенным носителем молибдена и ванадия. Главным носителем служат глинистые минералы, представленные в основном гидрослюдами, очевидно, в разной степени перекристаллизованными в процессе дегидратации.

По содержанию полезных компонентов наиболее богатыми являются аргиллиты юго-западной части месторождения (рис. 1).

Промышленное использование любого полезного ископаемого из вскрышных пород целесообразно, если дополнительные расходы, связанные с его совместной с фосфоритами добычей, вместе с расходами на его переработку экономически оправданы (Хабихт, 1969). При этом строго следует исходить из возможной потребности народного хозяйства в данном сырье:

Ввиду отсутствия в настоящее время потребности в глауконите йоаской и глине варангуской пачек, основное значение приобретают карбонатные породы и аргиллиты.

Исходными для геолого-экономической оценки совместной добычи фосфоритов, карбонатных пород и аргиллитов приняты следующие данные: а) проектная мощность карьера фосфоритной руды - 5 млн. $т$ в год; б) срок эксплуатации карьера - 30 лет; в) максимально допустимая мощность вскрышных пород при открытой разработке - $30 \mathrm{~m}$. Поскольку месторождение фосфоритов Тоолсе отличается изменчивой мощностью вскрышных пород (в особенности карбонатных), которая увеличивается в южном направлении, то в его пределах выделены три горнотехнические зоны: I зона имеет мощность вскрыши фосфоритов до 20 ж; II зона - до $25 \mu$; III зона -- 25-30 $\mu$. Все три зоны предусматривается эксплуатировать одновременно. Для каждой из них вычислена стоимость разработки $1 \mu^{2}$ карьерной площади при всех возможных варнантах совместной с фосфоритами добычи вскрышных пород.

За себестоимость добычи каждого конкретного полезного ископае. мого вскрыши взяты расходы, связанные только с его разработкой самостоятельным карьерным уступом, поскольку фосфорит как главное полезное ископаемое будет добываться вне зависимости от полезного использования вскрышных пород. 
Следует указать, что сырье, аналогичное карбонатным породам месторождения Тоолсе, развито по всей приглинтовой полосе Северной Эстонии и разрабатывается 5 карьерами. Поэтому экономическая целесообразность совместной разработки известняков с фосфоритами в Тоолсе практически определяется себестоимостью их добычи. Обусловливаемые технологией переработки эксплуатационные расходы при производстве щебня, а также капитальные затраты соответствуют таковым в специализированном карьере. Согласно исходным данным ежегодный выход карбонатных пород в карьере Тоолсе составляет в среднем 14 млн. $M^{3}$ (из них около 8 млн. $\mu^{3}$ пригодны для использования в условиях валовой выемки). В 1980 году и прогнозно до 2000 года может быть использовано максимально 2,3 млн. $\boldsymbol{M}^{3 / 20 \partial}$ известня ков месторождения Тоолсе, из них 1 млн. мзігод строительных и

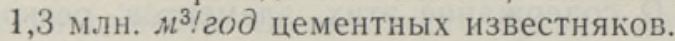

Расчеты показывают, что дополнительные расходы при добыче карбонатных пород самостоятельным карьерным уступом будут незначительными - в любом случае меньшими, чем при добыче в специализированном карьере. Однако транспортные условия крупного карьера гораздо сложнее (длина перевозок до $8,8 \kappa \mu$ ) и это обусловливает более

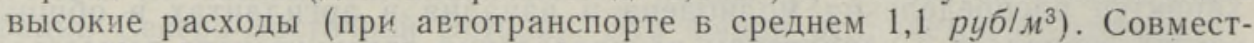
ная с фосфоритами добыча карбонатных пород для производства щебня и цемента экономически оправдана только в случае снижения транспортных расходов франко-промплощадка до 0,7 pyб/. ${ }^{3}$. Это значит, что дальность перевозок автотранспортом не должна превышать $4,5 \kappa$. . Снизить транспортные расходы вполне реально за счет сближения перерабатывающего узла и места разработки или при использовании более дешевого вида транспорта (транспортеры, железная дорога и т. д.). Окончательное инженерно-техническое решение вопроса возможно на стадии проектных работ.

Совсем иного подхода требует оценка экономической целесообразности слвместной с фосфоритами разработки аргиллитов. Согласно технологии переработки аргиллитов, разработанной в Институте химии АН ЭССР, из них можно получить комплексно несколько конечных продуктов. Подобное сырье с аналогичным сочетанием полезных компонентов в СССР не разрабатывается. Так как общепринятая методика распределения затрат, необходимых для одновременного производства нескольких видов продукции отсутствует, то экономическая целесообразность использования аргиллитов определялась суммарными затратами на добычу и переработку 1 т исходных аргиллитов. Согласно исходным данным годовой выход вскрышных аргиллитов составляет 2 млн. т. В настоящее время имеется потребность в продуктах, получаемых из аргиллитов. Проведенные впервые ориентировочные экономические расчеты показали, что совместная с фосфоритами добыча и комплексная переработка аргиллитов для получения алюмо-калиевых квасцов и некоторых элементов (Мо, V и др.) с попутным производством электроэнергии и серной кислоты экономически оправданы - срок окупаемости капитальных затрат ниже нормативного.

Хотя расчеты являются предеарительными, и выход полезных компонентов на 1 т исходных аргиллитов в промышленных условиях, как правило, бывает ниже лабораторного, результаты проведенной работы убедительно указывают на перспективность использования аргиллита в качестве нового вида комплексного полезного ископаемого.

На основе проведенных исследований авторами разработан рациональный вариант комплексной разработки месторождения Тоолсе (рнс. 2): 1) добычу основного ископаемого - фосфоритов, учитывая 
целесообразность совместной разработки вскрышных карбонатных пород, следует производить одновременно в пределах всех трех горнотехнических зон; 2) добычу аргиллитов надо производить самостоятельным карьерным уступом во всех зонах; 3) в пределах второй горнотехнической зоны предусматривается разработка верхней части разреза карбонатных пород (ласнамягиская свита и азериские слои) самостоятельным карьерным уступом высотой $5 \mathrm{M}$, что покроет годовую потребность (1 млн. $\boldsymbol{u}^{3}$ ) в строительном сырье; 4) в пределах третьей горнотехнической зоны также предусматривается разработка верхней части разреза карбонатных пород (ухакуская свита и верхняя часть ласнамягиской свиты), пригодных для производства цемента. Потребность в этом сырье -- 1,3 млн. $\boldsymbol{M}^{3 / 20 \partial-б у д е т ~ п о к р ы т а ~ п р и ~ в ы с о т е ~ к а р ь е р н о г о ~}$ уступа $6 \mu$.

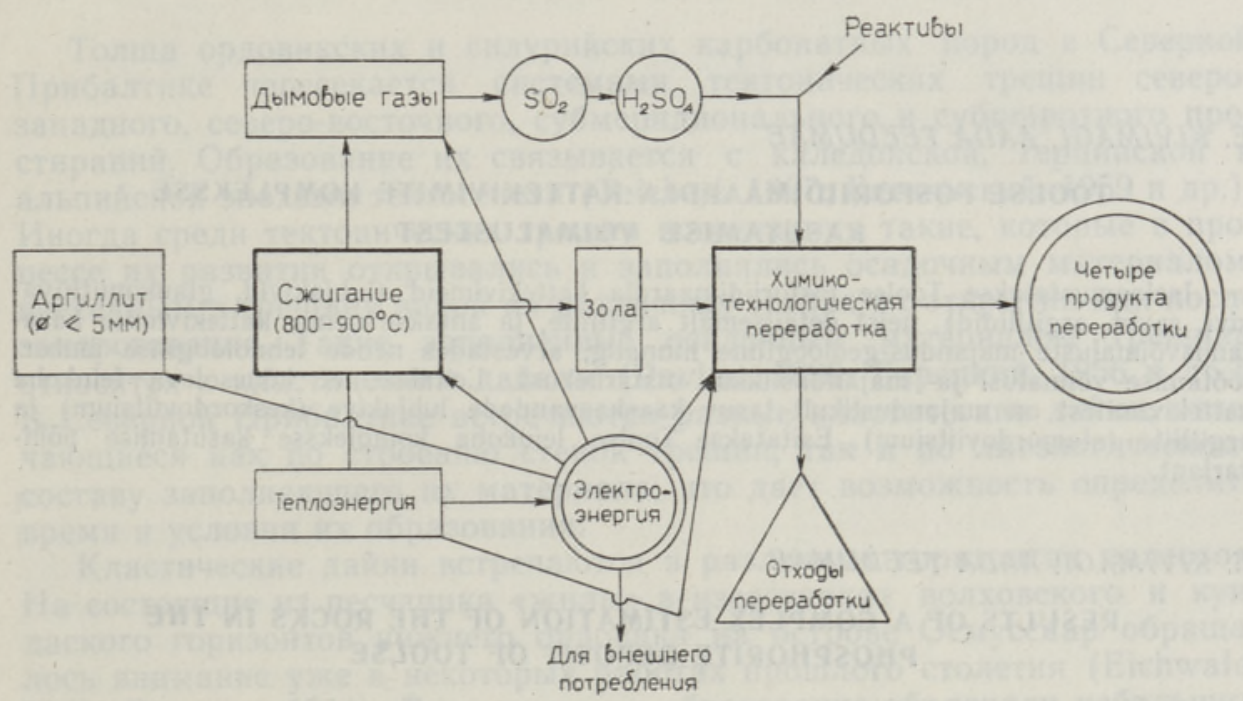

Рис. 3. Принциниальная схема комплексной переработки аргиллитов месторождения Тоолсе.

На основе результатов, а также технологических испытаний (Институт химии АН ЭССР, Институт термофизики и электрофизики АН ЭССР), геологических исследований и экономических расчетов, проведенных авторами, предлагается следующий вариант принципиальной схемы комплексной переработки аргиллитов месторождения Тоолсе (рис. 3). Измельченный (до 5 мм) аргиллит в первом технологическом узле сжигается в топках с кипящим слоем. Образующееся при этом тепло используется для выработки электроэнергии, идущей на внугренние и внешние нужды. Из дымовых газов выделяют сернистые соединения, которые используются для производства серной кислоты. Зола аргиллитов направляется во второй технологический узел, где после сложной химико-технологической переработки из нее выделяются алюмо-калиевые квасцы и некоторые микроэлементы. Твердые остатки переработки можно использовать для производства строительных материалов. 


\section{ЛИ ТЕРА Т Р А}

Ба уко в С. 1970. Актуальные вопросы экокамической геологии Прибалтийского сланцевого бассейна. Изв. АН ЭССР, Хим, Геол., 19, № 1.

В и й р а В., К и ви м г и Э., Л оог А. 1970. О литологии и возрасте варангуской пачки (тремадок Северной Эстонии). Изв. АН ЭССР, Хим. Геол., 19, № 2.

Кальо Д., Ки в и я г и Э. 1970. О раопределении граптолитов в диктионемовом сланце Эстонни и разновозрастности его фаций. Изв. АН ЭССР, Хим. Геол., 19. № 4.

Мустйыги $Э$. 1970. Месторождение фосфоритов Тоолсе (геолого-экономический обзор). Изв. АН ЭССР, Хим. Геол., 19, № 1.

$\mathrm{X}$ аб ихт К. 1969. Об экономике использования сложных месторождений. Изв. АН ЭССР, Общєственные науки, 19, № 2.

Управление геологии

Совета Министров Эстонской ССР
Поступила в редакцию

$18 / \mathrm{I} 1971$

\section{E. KIVIMÄGI, AADA TEEDUMAE}

\section{TOOLSE FOSFORIIDIMAARDLA KATTEKIVIMITE KOMPLEKSSE KASUTAMISE VÕIMALUSTEST}

Iseloomustatakse Toolse fosforiidimaardla kattekivimeid (lubjakivid, glaukoniitliivakivi, savid, argilliidid), neist detailsemalt argilliite, ja antakse nende kattekivimite kasutamisvõimaluste majandus-geoloogiline hinnang, arvestades nende tehnoloogilise ümbertöötamise võimalusi ja majanduslikku otstarbekust. Leitakse, et kõnesoleva leiukoha kattekivimitest on majanduslikult tasuv kaaskaevandada lubjakive (keskordoviitsium) ja argilliite (alamordoviitsium). Esitatakse Toolse leiukoha kompleksse kasutamise pöhivariant.

\section{E. KIVIMÄGI, AADA TEEDUMAE}

\section{RESULTS OF A COMPLEX ESTIMATION OF THE ROCKS IN THE PHOSPHORITE DEPOSIT OF TOOLSE}

The authors consider the problems of a complex exploitation of the rocks in the phosphorite deposit of Toolse (Fig. 1), under the conditions of open mining. It has been stated that the carbonate rocks of the Middle Ordovician are suitable for producing building materials and cement. The glauconite sandstones and aleurolites of the Leetse Stage contain about 60 per cent of glauconite. The clays of the Varangu Member of the Ceratopygeous Stage, however, contain a heightened amount of alkaline matter for which reason they cannot be used in the production of cement. The graptolytic argyllites of the Türisalu Member, of the same stage, seem to offer propitious possibilities for complex mining, the main components in them being some rare and dispersed elements (molybdenum, vanadium, and others), whose content in the argyllites varies in dependence on the lithological character of the rock.

A principal scheme of a complex processing of the argyllites has been devised (Fig. 3).

The possibilities and the rational scope of a complex working up of the carbonate rocks are discussed.

The authors propose an economically grounded scheme of a complex exploitation of the phosphorite deposit of Toolse (Fig. 2). 